\title{
Sicherungsinstrumente beim Grundstückserwerb
}

Eine rechtsvergleichende Betrachtung der Rechte an Grundstücken, der Grundstücksregister und des Grunderwerbsverfahrens in Deutschland und den Vereinigten Staaten von Amerika

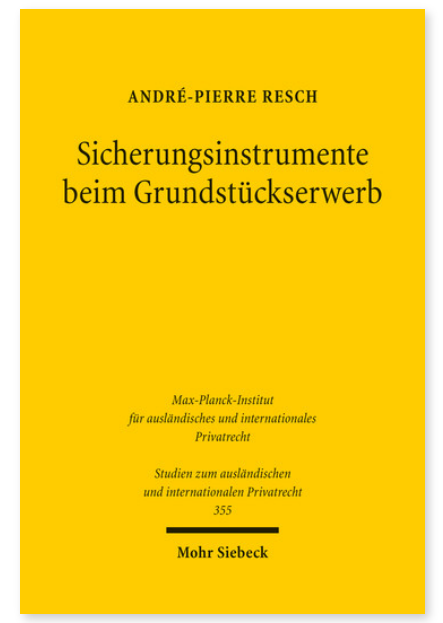

2016. XXIX, 498 Seiten. StudIPR 355

ISBN 978-3-16-154063-9

DOI 10.1628/978-3-16-154063-9

eBook PDF $99,00 €$

ISBN 978-3-16-154042-4

fadengeheftete Broschur 99,00€
Welche Instrumente stellen die deutsche und US-amerikanische Rechtsordnung und Praxis zur reibungslosen Übertragung von Grundeigentum zur Verfügung? Ausgehend von den rechtlichen und rechtstatsächlichen Rahmenbedingungen stellt André-Pierre Resch in einem Systemvergleich die in Deutschland und den Vereinigten Staaten von Amerika zur Verfügung stehenden Sicherungsinstrumente funktional gegenüber und ermittelt das jeweils mögliche bzw. in der Praxis vorzufindende Sicherungsniveau. Der Autor vermittelt die vielschichtigen Zusammenhänge der historisch gewachsenen Systeme und kommt zu dem Ergebnis, dass das deutsche, durch formalisiertes Grundbuchverfahren und Mitwirkung eines Notars geprägte System gegenüber dem auf die privatrechtliche »title insurance« zurückgreifenden US-amerikanischen Recht eine hohe Sicherheit gewährt und sich daher im Wettbewerb der Rechtsordnungen mehr als behaupten kann.

André-Pierre Resch Geboren 1982; Studium der Rechtswissenschaften an der Julius-Maximilians-Universität Würzburg; Wissenschaftlicher Mitarbeiter am Lehrstuhl für Bürgerliches Recht, Deutsches und Europäisches Handels- und Gesellschaftsrecht; Juristischer Vorbereitungsdienst am Landgericht Darmstadt mit Stationen in Mannheim und Windhuk, Namibia; seit 2014 Rechtsanwalt in Mannheim.

\section{Jetzt bestellen:}

https://mohrsiebeck.com/buch/sicherungsinstrumente-beim-grundstueckserwerb-9783161540639?no_cache=1 order@mohrsiebeck.com

Telefon: +49 (0)7071-923-17

Telefax: $+49(0) 7071-51104$ 